\title{
Pineal region tumors: a simplified management scheme
}

\author{
Mohamed A. Zaazoue ${ }^{1} \cdot$ Liliana C. Goumnerova ${ }^{1}$
}

Received: 10 June 2016 / Accepted: 26 June 2016 / Published online: 30 July 2016

(C) Springer-Verlag Berlin Heidelberg 2016

Tumors of the pineal region are rare and their optimal management remains controversial. In this editorial, we propose a simplified and stratified management scheme for tumors in this region.

\section{Incidence, presentation, and different types of pineal region tumors}

Pineal region tumors comprise $2.5-8.5 \%$ of pediatric intracranial tumors, being more common in the Asian populations $[1,2]$. These tumors are diverse in cell origin [3, 4], most commonly germ cell tumors (GCT) followed by pineal parenchymal tumors (PPT) (Fig. 1).

Patients usually present with obstructive hydrocephalus, symptoms/signs of brainstem compression, or evidence of precocious puberty or diabetes insipidus from metachronous GCTs, which are bifocal tumors occurring in the pineal and suprasellar regions simultaneously $[5,6]$. Brain and whole spine MRI with and without contrast should always be performed upon presentation (Fig. 2 and cover image) and prior to any procedure to assess for extent of disease [7].

Liliana C. Goumnerova

liliana.goumnerova@childrens.harvard.edu

1 Department of Neurosurgery, Boston Children's Hospital, 300 Longwood Avenue, Hunnewell 2, Boston, MA 02115, USA

\section{Management of GCTs}

\section{Role of markers}

Specific proteins, namely alpha-fetoprotein (AFP) and beta human chorionic gonadotropin ( $\beta \mathrm{hCG}$ ), are secreted by nongerminomatous GCTs (NGGCTs) or immature teratomatous elements and can be detected both in serum and/or cerebrospinal fluid (CSF) [8]. These markers can be used to diagnose NGGCTs even without tissue confirmation thereby avoiding surgery at presentation and its associated complications. Markers can also be used to reflect prognosis, evaluate response to treatment, and monitor disease recurrence [9-11].

AFP is secreted by yolk sac tumors mainly, as well as embryonal carcinomas and immature teratomas. $\beta \mathrm{hCG}$ is secreted primarily by choriocarcinomas and by some embryonal carcinomas [12].

Elevations of serum or CSF AFP $>10 \mathrm{ng} / \mathrm{ml}$ and/or $\beta$ hCG $>50 \mathrm{mIU} / \mathrm{ml}$ is considered marker-positive [7]. Usually, germinomas (GGCTs) and mature teratomas do not have elevated markers [13]. A subgroup of germinomas with a syncytiotrophoblastic component $(\mathrm{G} / \mathrm{S})$ can secrete $\beta$ hCG and have a slightly poorer prognosis compared to pure GGCTs necessitating treatment similar to that of NGGCT [14].

The AFP elevations in serum and CSF tend to correlate with each other. $\beta$ hCG elevations in the CSF are not always associated with identical serum elevated levels. Therefore, it is necessary to obtain CSF samples in patients whose serum $\beta$ hCG levels are not diagnostic [8].

Markedly elevated AFP levels (>1000 ng/ml) appear to have poorer prognosis. In contrast, marked elevations in $\beta$ hCG levels $(>1000 \mathrm{mIU} / \mathrm{ml})$ did not reflect the same prognostic significance [11]. 
Fig. 1 Pathology of pineal region tumors, incidence, and prognosis $[1,2,4,5,7,14]$. GCTs germ cell tumors, $N G G C T$ nongerminomatous germ cell tumor, $P P T$ pineal parenchymal tumor

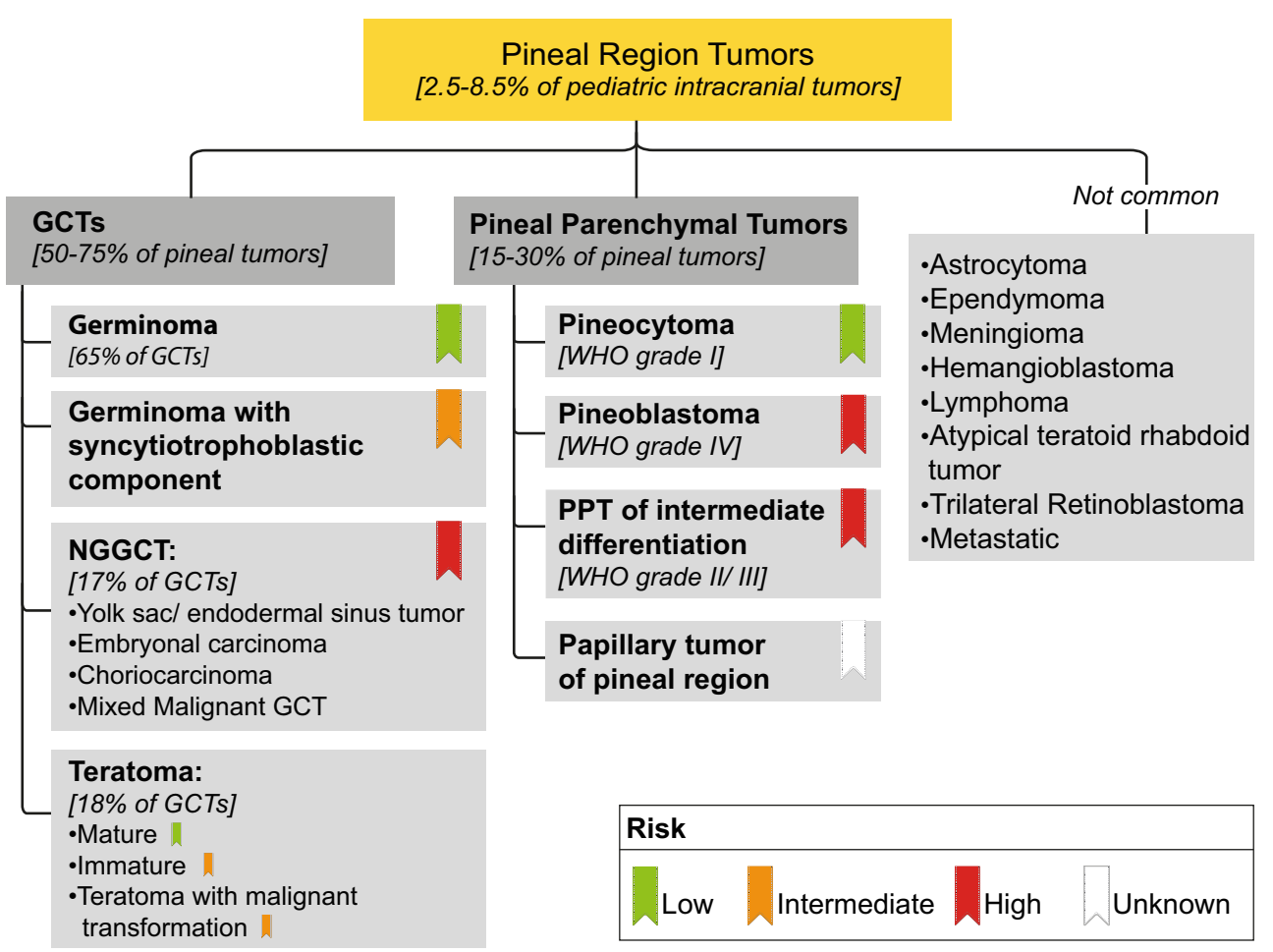

In non-secreting pineal region tumors, tissue diagnosis is always required to guide further management [7].

\section{Endoscopy: ETV, CSF sampling, biopsy, and resection}

The introduction of neuroendoscopy has helped improve the morbidity and mortality of procedures in the pineal

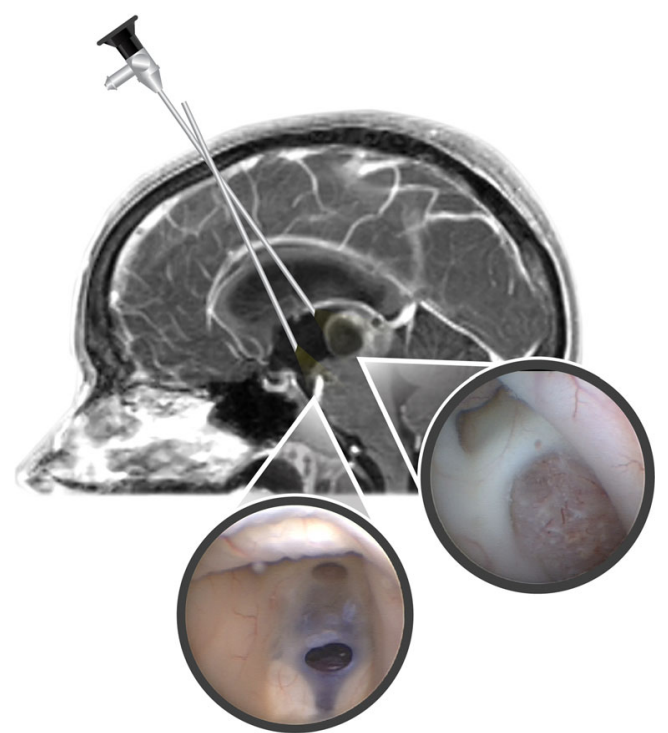

Fig. 2 Sagittal T1 weighted image MRI with contrast enhancement demonstrating a pineal region tumor, with endoscope illustrations and intraoperative endoscopic views of the following: (left) the floor of the third ventricle after an endoscopic third ventriculostomy has been performed; (right) pineal region tumor obstructing the aqueduct of Sylvius region [15]. For patients presenting with obstructive hydrocephalus, the initial management is endoscopic third ventriculostomy (ETV), inspection of the ventricular system for evidence of CSF dissemination, and biopsy of the tumor (if technically feasible) along with CSF sampling for cytology and markers (Fig. 2 and cover image) [16]. If possible, the endoscope can also be used to resect the tumor, for example, in small and avascular tumors.

ETV should be the first line of treatment for obstructive hydrocephalus in patients with tumors in the pineal/tectal area [17]. However, if not available, placement of a ventriculoperitoneal shunt can be performed in the initial management of the hydrocephalus but carries the risk of peritoneal dissemination [18].

If ETV and tumor biopsy will be performed in the same session, the ETV should be done first to avoid obscuration of the operative field by bleeding from the tumor after biopsy [19].

\section{Chemotherapy, radiotherapy, and combination}

GGCTs are highly radiosensitive, therefore, can be treated with radiotherapy alone. However, in order to reduce the long-term side effects of radiotherapy, adjuvant chemotherapy can be added. This has shown to lower the needed dose and field of radiotherapy while achieving comparable outcomes. In localized GGCTs, controversy exists regarding dose and field (whole ventricle versus whole brain) of radiotherapy $[20,21]$. In recurrent or 
disseminated GGCTs, craniospinal irradiation (CSI) is utilized [6].

NGGCTs and teratomas (except mature teratoma) are more aggressive tumors, so management usually incorporates a combination of chemotherapy followed by CSI [22]. In contrast, management of mature teratomas can be through surgery alone if gross total resection is achieved, without the need for adjuvant therapy [23]. Mixed GCTs are managed according to the most malignant component present in the tumor [24].

Residual mass remaining after anti-neoplastic therapy could reflect fibrosis or necrosis as a consequence of therapy or could be residual tumor. If residual tumor is suspected, "second look surgery" is performed to resect the mass and achieve NED (no evidence of disease). In some cases, this may require further chemotherapy to accomplish NED [19, 25].

\section{Growing teratoma syndrome}

Occasionally, progression can be detected either during or following initiation of chemotherapy and after normalization of tumor markers. This condition is referred to as growing teratoma syndrome (GTS) and is more common in immature teratomas and NGGCTs. Early attempt at complete excision is the treatment of choice, followed by standard treatment of NGGCTs [26].

The algorithm shown in Fig. 3 acts as a step-by-step guide towards management of patients presenting with pineal region
Fig. 3 Algorithm for step-bystep management of a pineal region tumor. CSF cerebrospinal fluid, ETV endoscopic third ventriculostomy, $+v e$ positive, $-v e$ negative, $G G C T$ germinomatous germ cell tumor, $N G G C T$ non-germinomatous germ cell tumor, $G / S$ germinoma with syncytiotrophoblastic component, Chemo. chemotherapy

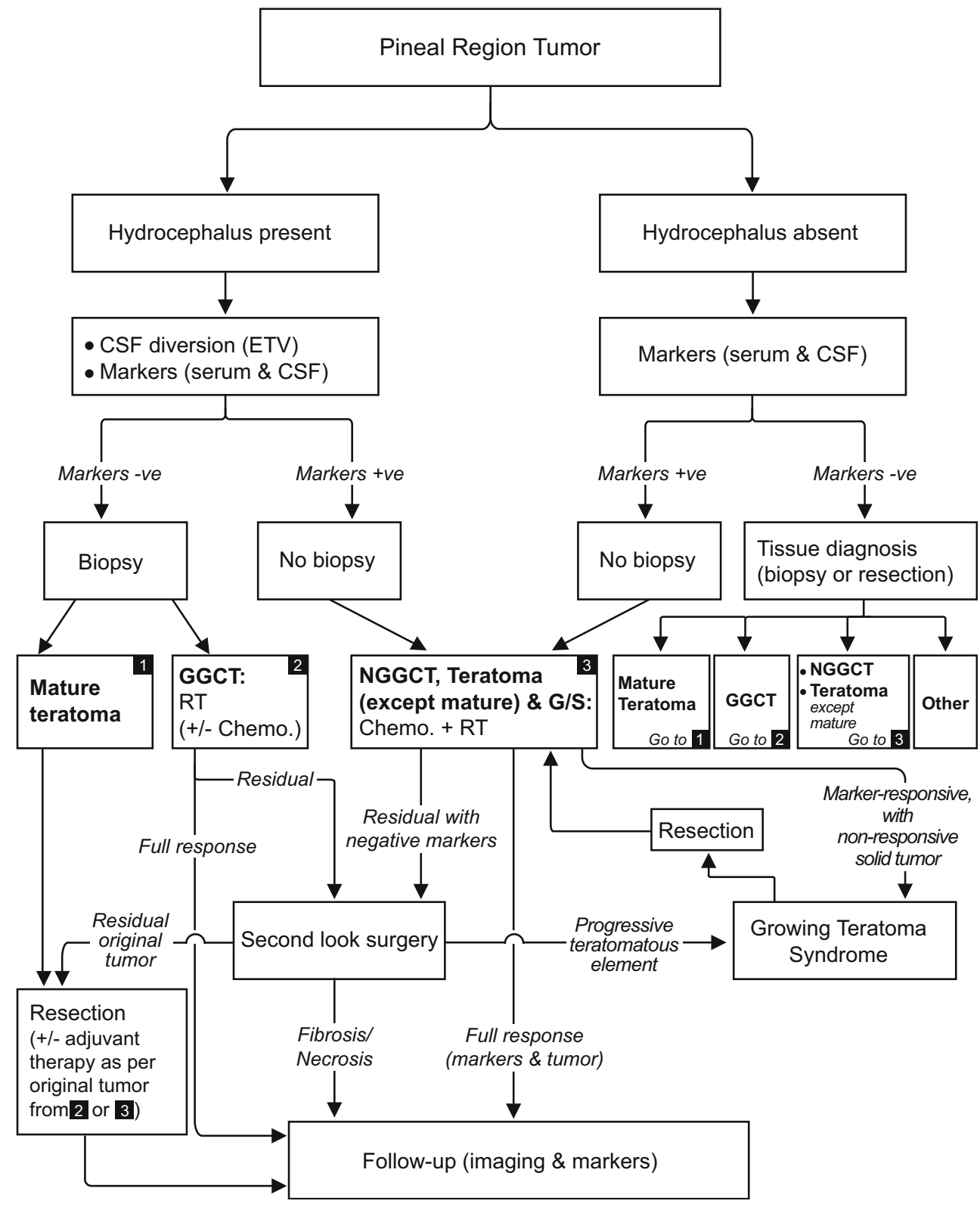


tumors. Long-term follow-up is done using routine imaging and marker surveillance.

\section{Role of open surgery}

With the advancements in endoscopic neurosurgical procedures and stereotactic biopsies and the ability to reach the diagnosis by markers, the role of open surgery to obtain a tissue diagnosis has declined [27]. However, if tumor resection/debulking is indicated after tissue diagnosis, open surgery is still a viable option. Several approaches can be used to access the pineal region, including interhemispheric transcallosal, suboccipital transtentorial, and supracerebellar infratentorial. These are determined by the surgeon's preference, risk of morbidity, and tumor location [18].

\section{Molecular oncology of GCTs}

The activation of the MAPK pathway by KIT or RAS mutations plays a role in the pathogenesis of GGCTs. Such mutations are mutually exclusive and are positively correlated with KIT mRNA overexpression and chromosomal instability [28]. The importance of these findings is that molecular targeting agents, such as imatinib, which is an inhibitor of specific tyrosine kinases, including KIT, can be used in the management of GGCTs that harbor KIT mutations. These alternative management options can help avoid long-term adverse effects associated with radiotherapy which include neurocognitive impairment, secondary neoplasms, radiation-induced occlusive vasculopathy, and endocrinological dysfunctions [29, 30].

The relationship between KIT mutations and the prognosis of GGCTs is controversial [31]. However, some suggest that patients with these mutations require long-term follow-up due to the risk of secondary GCTs [29].

Similar molecular and genetic findings have not been clearly uncovered in the pathogenesis of NGGCTs [28].

Further genetic studies are required to understand the pathogenesis of GCTs and subsequently improve the outcomes of these tumors, especially those who fail conventional treatments [28, 29, 31].

\section{Management of PPTs}

\section{Pineocytomas}

Pineocytomas are infrequently seen in the pediatric population and their treatment is primarily surgical. Pineocytomas in the tectal region can present with obstructive hydrocephalus that requires CSF diversion using ETV. Asymptomatic pineocytomas can be managed conservatively; and if enlarged, gross total resection is curable. In case of subtotal excision, long-term follow-up is required [32].

\section{Pineoblastomas (PBs)}

These are considered primary neuroectodermal tumors (PNETs) and are classified as WHO grade IV. PBs are aggressive tumors (especially when presenting in children $<3$ years) that frequently metastasize. Optimal management includes gross total resection, whenever possible, followed by combination chemotherapy and CSI [33-35].

\section{Less common tumors in pineal region}

These tumors are shown in Fig. 1 and are managed according to their primary pathology.

\section{Conclusion}

Pineal region tumors in the pediatric population are primarily GCTs where diagnosis can be made via serum and CSF markers and can help guide therapy. These markers are also utilized in the monitoring of response to therapy and longterm follow-up.

Advancements in neuroendoscopy have led to the ability to simultaneously treat the hydrocephalus (ETV) and obtain tissue diagnosis, when necessary, thereby obviating the need for more invasive and morbid procedures.

This paper provides a schema for the management of these tumors at time of presentation that will hopefully assist in the initial management and guide therapy once pathologic diagnosis is made. The subsequent management of this diverse group of tumors is dependent on response to therapy and is tailored to the original pathology.

Better understanding of the molecular genetics behind the pathogenesis of GCTs is required to introduce safer treatment modalities and improve outcomes.

\section{Compliance with ethical standards}

Conflict of interest The authors have no conflict of interest or financial disclosures.

\section{References}

1. Ostrom QT, Gittleman H, Fulop J, Liu M, Blanda R, Kromer C, Wolinsky Y, Kruchko C, Barnholtz-Sloan JS (2015) CBTRUS Statistical Report: primary brain and central nervous system tumors diagnosed in the United States in 2008-2012. Neuro Oncol 17(Suppl 4):iv1-iv62

2. Wong TT, Ho DM, Chang KP, Yen SH, Guo WY, Chang FC, Liang ML, Pan HC, Chung WY (2005) Primary pediatric brain tumors: 
statistics of Taipei VGH, Taiwan (1975-2004). Cancer 104:21562167

3. Hirato J, Nakazato Y (2001) Pathology of pineal region tumors. J Neurooncol 54:239-249

4. Louis DN, Ohgaki H, Wiestler OD, Cavenee WK, Burger PC, Jouvet A, Scheithauer BW, Kleihues P (2007) The 2007 WHO classification of tumours of the central nervous system. Acta Neuropathol 114:97-109

5. Jennings MT, Gelman R, Hochberg F (1985) Intracranial germ-cell tumors: natural history and pathogenesis. J Neurosurg 63:155-167

6. Dhall G, Khatua S, Finlay JL (2010) Pineal region tumors in children. Curr Opin Neurol 23:576-582

7. Fontana EJ, Garvin J, Feldstein N, Anderson RC (2011) Pediatric considerations for pineal tumor management. Neurosurg Clin $\mathrm{N}$ Am 22:395-402, ix

8. Qaddoumi I, Sane M, Li S, Kocak M, Pai-Panandiker A, Harreld J, Klimo P, Wright K, Broniscer A, Gajjar A (2012) Diagnostic utility and correlation of tumor markers in the serum and cerebrospinal fluid of children with intracranial germ cell tumors. Childs Nerv Syst 28:1017-1024

9. Baranzelli MC, Kramar A, Bouffet E, Quintana E, Rubie H, Edan C, Patte C (1999) Prognostic factors in children with localized malignant nonseminomatous germ cell tumors. J Clin Oncol 17: 1212

10. Perkins GL, Slater ED, Sanders GK, Prichard JG (2003) Serum tumor markers. Am Fam Physician 68:1075-1082

11. Lee D, Suh YL (2010) Histologically confirmed intracranial germ cell tumors; an analysis of 62 patients in a single institute. Virchows Arch 457:347-357

12. Packer RJ, Cohen BH, Cooney K (2000) Intracranial germ cell tumors. Oncologist 5:312-320

13. Luther N, Edgar MA, Dunkel IJ, Souweidane MM (2006) Correlation of endoscopic biopsy with tumor marker status in primary intracranial germ cell tumors. J Neurooncol 79:45-50

14. Matsutani M, Sano K, Takakura K, Fujimaki T, Nakamura O, Funata N, Seto T (1997) Primary intracranial germ cell tumors: a clinical analysis of 153 histologically verified cases. J Neurosurg $86: 446-455$

15. Mottolese C, Szathamari A, Beuriat PA, Grassiot B, Simon E (2015) Neuroendoscopy and pineal tumors: a review of the literature and our considerations regarding its utility. Neurochirurgie 61: $155-159$

16. Morgenstern PF, Souweidane MM (2013) Pineal region tumors: simultaneous endoscopic third ventriculostomy and tumor biopsy. World Neurosurg S18.e19

17. Morgenstern PF, Osbun N, Schwartz TH, Greenfield JP, Tsiouris AJ, Souweidane MM (2011) Pineal region tumors: an optimal approach for simultaneous endoscopic third ventriculostomy and biopsy. Neurosurg Focus 30:E3

18. Kennedy BC, Bruce JN (2011) Surgical approaches to the pineal region. Neurosurg Clin N Am 22:367-380, viii

19. Souweidane MM, Krieger MD, Weiner HL, Finlay JL (2010) Surgical management of primary central nervous system germ cell tumors: proceedings from the Second International Symposium on Central Nervous System Germ Cell Tumors. J Neurosurg Pediatr 6:125-130

20. Khatua S, Dhall G, O’Neil S, Jubran R, Villablanca JG, Marachelian A, Nastia A, Lavey R, Olch AJ, Gonzalez I, Gilles F, Nelson M, Panigrahy A, McComb G, Krieger M, Fan J, Sposto R, Finlay JL
(2010) Treatment of primary CNS germinomatous germ cell tumors with chemotherapy prior to reduced dose whole ventricular and local boost irradiation. Pediatr Blood Cancer 55:42-46

21. Rogers SJ, Mosleh-Shirazi MA, Saran FH (2005) Radiotherapy of localised intracranial germinoma: time to sever historical ties? Lancet Oncol 6:509-519

22. Matsutani M, Ushio Y, Abe H, Yamashita J, Shibui S, Fujimaki T, Takakura K, Nomura K, Tanaka R, Fukui M, Yoshimoto T, Hayakawa T, Nagashima T, Kurisu K, Kayama T (1998) Combined chemotherapy and radiation therapy for central nervous system germ cell tumors: preliminary results of a Phase II study of the Japanese Pediatric Brain Tumor Study Group. Neurosurg Focus 5:e7

23. Frappaz D, Conter CF, Szathmari A, Valsijevic A, Mottolese C (2015) The management of pineal tumors as a model for a multidisciplinary approach in neuro-oncology. Neurochirurgie 61:208211

24. Kyritsis AP (2010) Management of primary intracranial germ cell tumors. J Neurooncol 96:143-149

25. Echevarria ME, Fangusaro J, Goldman S (2008) Pediatric central nervous system germ cell tumors: a review. Oncologist 13:690-699

26. Kim CY, Choi JW, Lee JY, Kim SK, Wang KC, Park SH, Choe G, Ahn HS, Kim IH, Cho BK (2011) Intracranial growing teratoma syndrome: clinical characteristics and treatment strategy. J Neurooncol 101:109-115

27. Oi S, Shibata M, Tominaga J, Honda Y, Shinoda M, Takei F, Tsugane R, Matsuzawa K, Sato O (2000) Efficacy of neuroendoscopic procedures in minimally invasive preferential management of pineal region tumors: a prospective study. J Neurosurg 93:245-253

28. Fukushima S, Otsuka A, Suzuki T, Yanagisawa T, Mishima K, Mukasa A, Saito N, Kumabe T, Kanamori M, Tominaga T, Narita Y, Shibui S, Kato M, Shibata T, Matsutani M, Nishikawa R, Ichimura K (2014) Mutually exclusive mutations of KIT and RAS are associated with KIT mRNA expression and chromosomal instability in primary intracranial pure germinomas. Acta Neuropathol 127:911-925

29. Sakuma Y, Sakurai S, Oguni S, Satoh M, Hironaka M, Saito K (2004) c-kit gene mutations in intracranial germinomas. Cancer Sci 95:716-720

30. Jackson C, Jallo G, Lim M (2011) Clinical outcomes after treatment of germ cell tumors. Neurosurg Clin N Am 22:385-394, viii

31. Kamakura Y, Hasegawa M, Minamoto T, Yamashita J, Fujisawa $H$ (2006) C-kit gene mutation: common and widely distributed in intracranial germinomas. J Neurosurg 104:173-180

32. Clark AJ, Sughrue ME, Aranda D, Parsa AT (2011) Contemporary management of pineocytoma. Neurosurg Clin N Am 22:403-407, Ix

33. Tate MC, Rutkowski MJ, Parsa AT (2011) Contemporary management of pineoblastoma. Neurosurg Clin N Am 22:409-412, Ix

34. Mandera M, Marcol W, Kotulska K, Olakowska E, Golka D, Malinowska I, Pietrucha-Dutczak M, Olakowski M, LewinKowalik J (2010) Childhood pineal parenchymal tumors: clinical and therapeutic aspects. Neurosurg Rev 34:191-196

35. Gilheeney SW, Saad A, Chi S, Turner C, Ullrich NJ, Goumnerova L, Scott RM, Marcus K, Lehman L, De Girolami U, Kieran MW (2008) Outcome of pediatric pineoblastoma after surgery, radiation and chemotherapy. J Neurooncol 89:89-95 